\title{
Life Cycle Cost Analysis for Variable Refrigerant Flow (VRF) and Constant Refrigerant Flow (CRF) Air Conditioning Systems in Arid Climate: Case Study in Qatar
}

Georges Atallah, Dr. Faris Tarlochan

ga1912343@qu.edu.qa, faris.tarlochan@qu.edu.qa

\section{Abstract}

All over the world, there is a call to encourage sustainable energy thinking and implementation. In the heating, ventilation and air conditioning field, the rise of the variable refrigerant flow systems has made a big progress. This study presents a life-cycle cost analysis to evaluate the economic feasibility of constant refrigerant flow (CRF) in particular the conventional ducted unit air conditioning system and the variable refrigeran flow (VRF) system by using detailed cooling load profiles, initial, operating, and maintenance costs. Two operating hours scenarios are utilized and the present-worth value technique for life-cycle cost analysis is applied to an existing office building located in Qatar which can be conditioned by CRF and VRF systems. The results indicate that although the initial cost of the VRF system is higher than that of the CRF system, the presentworth cost of the VRF system is lower than that of the CRF system at the end of the lifetime due to lower operating costs. The implementation of these results on a national scale will promote the use of sustainable energy technologies such as the VRF system.

Keywords: Life cycle cost, Air-conditioning, variable refrigerant flow, constant refrigerant flow, sustainable energy
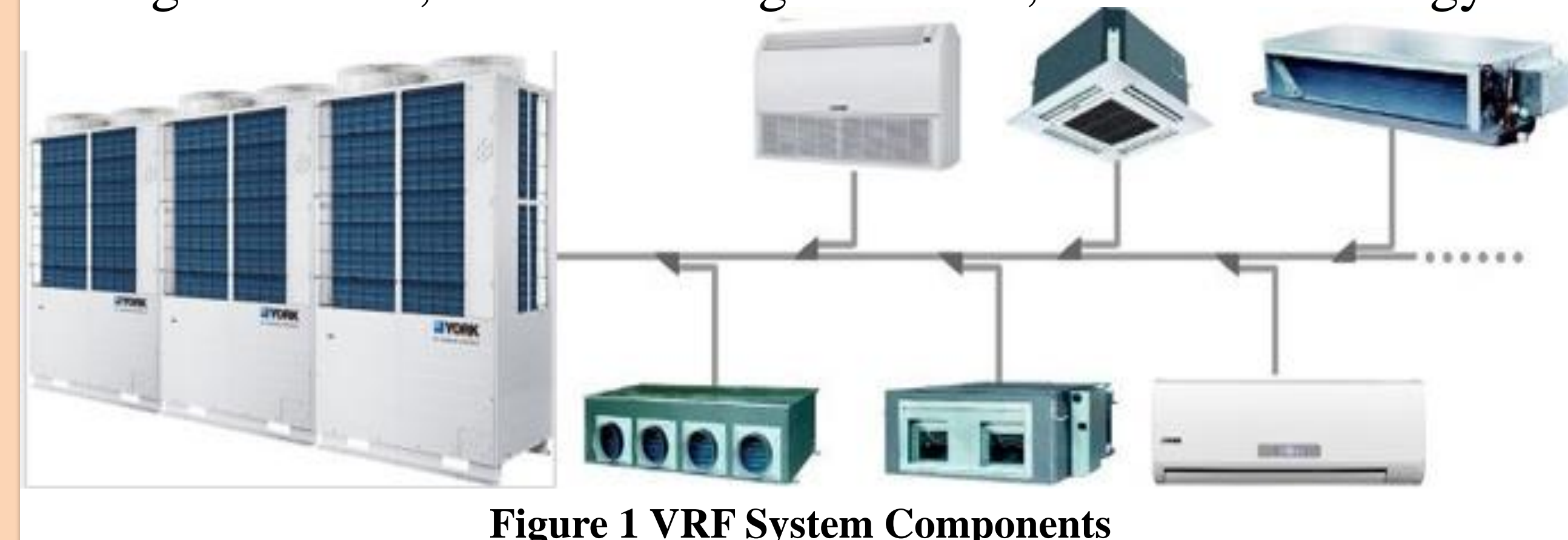

Significance of the Study

Identifying and applying sustainable energy sources for the cooling purpose is very crucial towards achieving Qatar's vision 2030. Such practices have a great impact on the environmental level as well as on the national budget related to the power grid infra structure and the total electrical energy consumption knowing that the air conditioning accounts for $60-70 \%$ of the Qatar's total electrical demand [4]. Another significant importance is the lack of studies on VRF systems in the GCC area in general and in Qatar in particular. Hence, this thesis will become a reference for the stakeholders who are linked to the energy sector such as governments, owners, design firms and contractors.

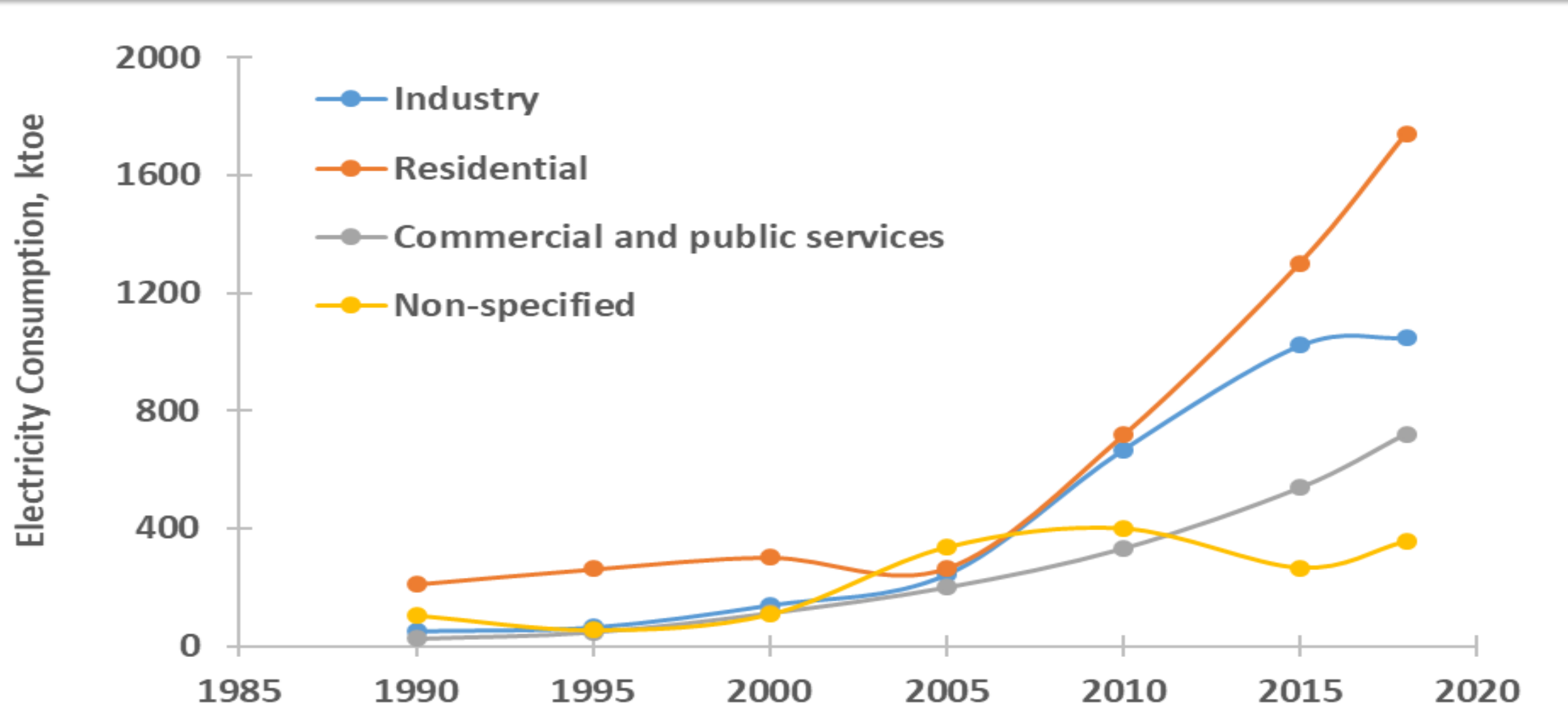

Figure 2 Electricity Consumption in Qatar by Sector

Methodology

Start

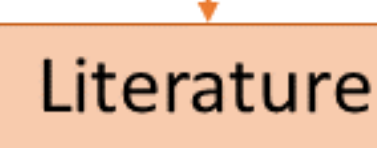

Review
VRF

Quantitative Analysis

(Case Study)

Life Cycle Cost

Analysis

Conclusion

End

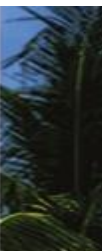

Data

Collection
The details of the operating cost for both scenarios are tabulated in Tables 1 and 2 . The operating cost of the CRF is $38 \%$ higher than the VRF for both scenarios. Next, the maintenance cost will be added and then the present worth value is used to determine the payback time over the years. The manpower needed to perform the maintenance works for both systems are almost identical because the number and capacities of indoor units are the same. Therefore, the cost of maintenance and spare parts used are the same except for the outdoor units since the number of CRF outdoor units is 137 compared to 24 outdoor units for the VRF system. There is an additional cost of 18,000 QAR for the CRF system due to failing compressors per year [25].

The initial, operating and maintenance costs for the two systems are developed in this study. A life cycle cost (LCC) analysis allows to compare the CRF and VRF systems. The life of each system is considered to be 15 years. LCC analysis is based on the following interest and inflation rates as depicted in Table 3. The present worth cost technique is used to compare the total costs (initial, operating and maintenance) of the two alternative systems (CRF and VRF) taking into account the two operating scenarios (scenario 1 and 2) over the 15 years period.

Table 3 Sensitivity analysis of varying inflation and interest rates

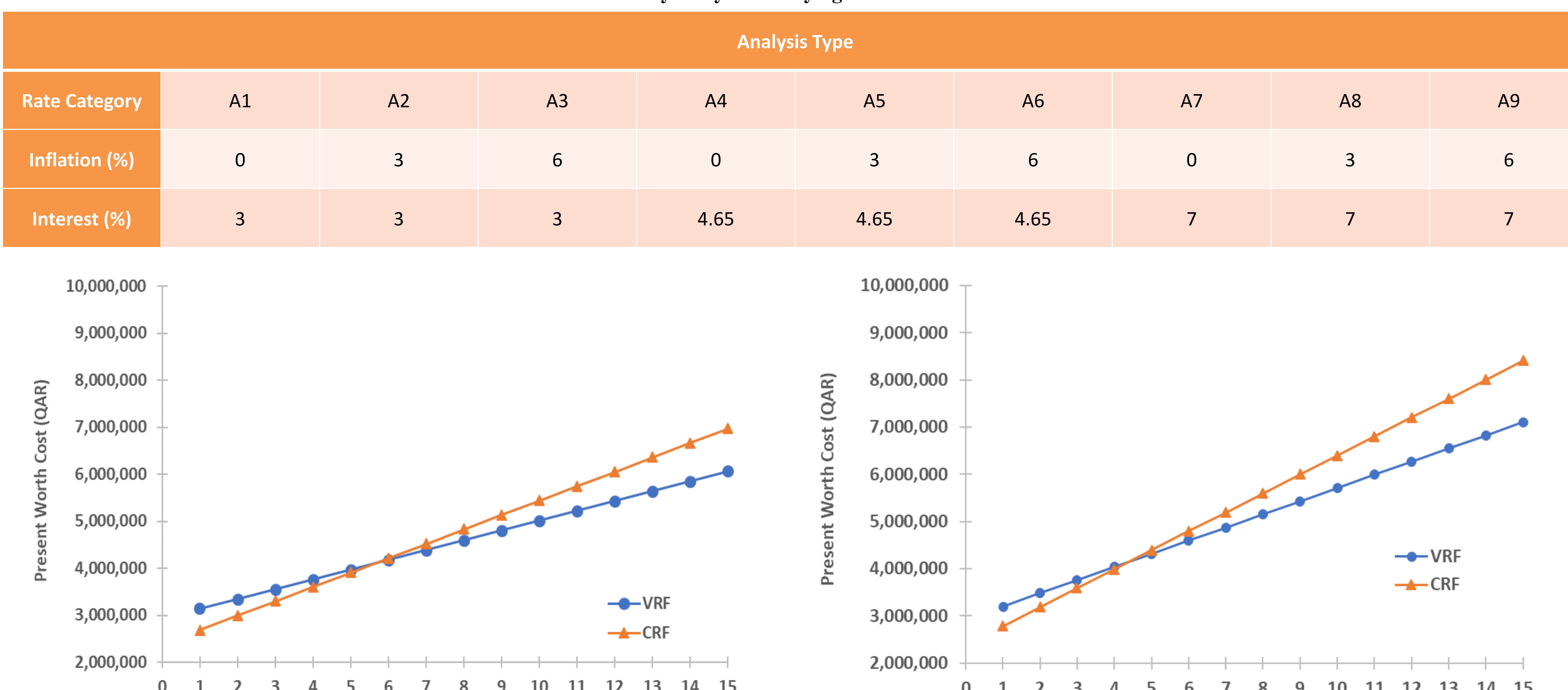

Figure 4 Present worth cost for scenario 1 (interest rate 3\%, inflation rate 3\%)

Figure 5 Present worth cost for scenario 2 (interest rate $3 \%$, inflation rate $3 \%$ )

Example of variation of overall present worth costs for both systems are shown in Fig. 4 and Fig. 5 for representation purpose. Based on Table 3, for scenario 1 (12 hours operation) the present worth cost for VRF system is lower by 7-15\% if compared to the CRF system and for scenario 2 (24 hours operation), the present worth cost for VRF system is lower by 10-18\% if compared to the CRF system. For longer operating hours, the VRF system shows a bigger advantage. The VRF cost is higher at the beginning but after a certain number of years (after 5 years), the VRF system becomes more economically efficient. The VRF system consumes less power input than the CRF system by $27 \%$ for both scenarios. This reduction can have a significant impact on a national level when implementing green building techniques such as the VRF technology in the air conditioning industry.

\section{Conclusion}

References

When comparing the VRF and CRF systems in this study, initial, operating and maintenance costs are calculated for Al Muftah Plaza building in Qatar. The present worth cost method and the LCC analysis are used for two different scenarios.

At the end of 15 years, the present worth cost of the VRF system is found to be always lower than the present worth cost of the CRF system, the conventional ducted units in our case. When the operating hours are longer, scenario 2, the VRF system shows a bigger economical advantage over the CRF system.

The power input needed for the VRF system is $27 \%$ lower than the CRF system which can make a tremendous impact on a national level when sustainable energy methods are implemented such as the VRF technology.

口init aris sats 回量的 